\title{
Highly Efficient and Greener Approach for Fluorinating Organic Compounds
}

\author{
SURENDER KUMAR DHINGRA $^{1 *}$, PURNIMA NAG ${ }^{2}$ and RAHUL SAXENA ${ }^{1}$ \\ ${ }^{1}$ Research and Development Centre, SRF Limited, Bhiwadi, Rajasthan-301019, India \\ ${ }^{2}$ Department of Chemistry, Jaipur National University, Jaipur, Rajasthan-302017, India \\ surender.dhingra@srf.com
}

Received 9 October 2015 / Accepted 28 October 2015

\begin{abstract}
The introduction of fluoride by nucleophilic aromatic substitution is found to be more effective when ionic liquids e.g. 1-butyl-3-methylimidazolium tetrafluoroborate and 1-butyl-3methylimidazolium hexafluorophosphate are used as a solvent. The use of the ionic liquids increased the yield and lowered the reaction temperature of similar fluorination reactions vis-a-vis organic solvents. In absence of any suitable solvent for fluorination reactions, the ionic liquids appear to be most suitable option especially for large scale. We propose a simple, efficient and green reaction protocol for the preparation of fluorinated organic compounds by sequential halogen exchange of aromatic in the presence of ionic liquids. The operational simplicity, low temperature, high yield, ecofriendly, safe, easily scalable processes with recyclability of ionic liquids are major benefits.
\end{abstract}

Keywords: Ionic liquids, Halex, Green chemistry, Fluorinated organic compounds.

\section{Introduction}

The last decade has witnessed an upsurge in the research activities related to green chemistry. Most of the effort in this direction has been focused on replacing the abundantly used volatile organic solvents (VOC) by suitable alternate solvent systems for easy chemical transformations with the minimum chemical waste and environmental pollution.

The ionic liquids such as 1-butyl-3-methylimidazolium tetrafluoroborate and 1-butyl-3methylimidazolium hexafluorophosphate have broad application as green solvent ${ }^{1-3}$. The most important reason is that, ionic liquids possess negligible vapor pressure and hence do not evaporate to environment. Secondly, they are good solvents for a whole range of inorganic and organic materials. Further, some of them are immiscible with organic solvents and therefore they provide a polar alternative with non-aqueous nature for two-phase systems. Lastly, ionic liquids can also be recycled to offer comparable performance in chemical transformations.

Fluorinated organic compounds are important building blocks in pharmaceuticals and agrochemicals and preferred over their non-fluorinated analogs ${ }^{4,5}$. The main reasons being broader spectrum of activity, lower toxicity and enhanced chemical and physical properties. An important method to prepare fluorinated organic compounds is by halogen-exchange 
(Halex) where a chloro- or bromo-group in the precursor is substituted by fluoride ${ }^{6,7}$. A number of metal fluorides can be used as nucleophilic fluorinating agents such as potassium fluoride, sodium fluoride, cesium fluoride etc., but potassium fluoride (KF) is preferred because of its ready availability and low $\operatorname{cost}^{8}$. Halex reactions are best carried out in polar aprotic solvents where the nucleophilicity of fluoride ion is higher, although at the expense of solubility. To achieve sufficient solubility, temperatures in the range of $240-300{ }^{\circ} \mathrm{C}$ are therefore required $d^{9,10}$. The general solvents used for halex reaction are acetonitrile, benzonitrile, dimethyl formamide, dimethyl sulphoxide, dimethyl acetamide and sulpholane ${ }^{11}$. Acetonitrile is used for low temperature reaction, whereas dimethyl formamide, dimethyl sulphoxide, dimethyl acetamide and sulpholane are preferred for high temperature reaction. Beyond boiling point, all the above solvents decompose to some extents forming tarry material and resulting in lower yield. Especially from industry view point, there is no preferred solvent for fluorination, as all lead to effluent generation, high cost and are difficult to recycle.

Therefore development of quick, widely applicable and environmentally green methodology for fluorination in ionic liquids is still an active area of research. In view of the above a simple, efficient and green reaction protocol for the preparation of fluorinated organic compounds has been developed in present investigation by halex reactions using ionic liquids.

\section{Experimental}

\section{Materials and Methods}

Raw materials were purchased from Sigma-Aldrich/ Spectrochem and used without further purification. IR spectra were recorded on a PERKIN ELMER infrared spectrophotometer. GCMS were recorded on 5975C inert XL MSD with Triple Axis Detector attached with 7890A GC system from AGILENT TECHNOLOGIES. GC purity were analyzed with HP-5 capillary column and authenticated with standard pure sample obtained from Sigma Aldrich. The GC data were reported in area percent. The synthesized compounds were characterized by ${ }^{1} \mathrm{H},{ }^{13} \mathrm{CNMR}$ and ${ }^{19} \mathrm{~F}$ NMR recorded on Bruker $(500 \mathrm{MHz})$ instrument using $\mathrm{CDCl}_{3}$ as solvent.

\section{Preparation of ionic liquids}

The imidazolium based ionic liquids with aliphatic side chains i.e. 1-butyl-3-methylimidazolium tetrafluoroborate (IL-1) and 1-butyl-3-methylimidazolium hexafluorophosphate (IL-2) were prepared according to the procedure described in literature ${ }^{12-14}$ (Scheme-1).

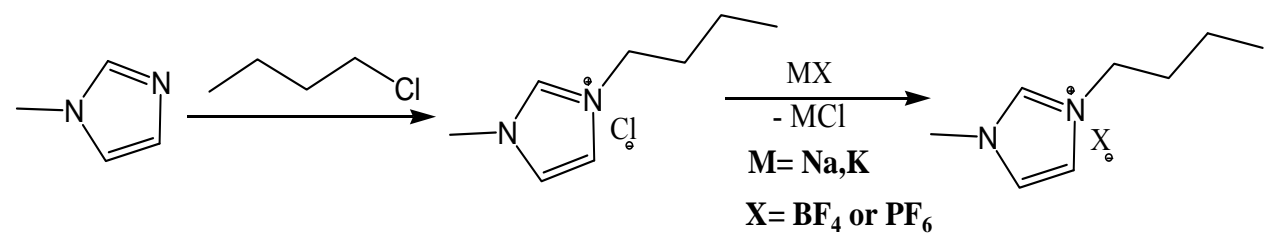

Scheme 1

\section{General procedure for the synthesis of fluorinated organic compound}

Spray dried potassium fluoride powder $(82.5 \mathrm{mmol})$ was added to ionic liquid-I $(168 \mathrm{mmol})$ at room temperature under nitrogen atmosphere to make slurry. Aromatic chloro compound (55 $\mathrm{mmol}$ ) was then added to the reaction mixture at room temperature. The reaction mixture was heated for 6-10 $\mathrm{h}$ at $150-200{ }^{\circ} \mathrm{C}$. GC analysis showed absence of starting material. The reaction mixture was cooled to $50-60{ }^{\circ} \mathrm{C}$ with simultaneous distillation of the product under vacuum. 
The residual ionic liquid was reused for several runs after regeneration (Scheme 2). Since the quantity of ionic liquid used was low therefore dichloromethane was added to assist removal of inorganic salts by filtration by increasing its flowability. The residual dichloromethane was distilled to regenerate the ionic liquid

Similar procedure was used for the synthesis of 4-fluoronitrobenzene, 2-fluoronitrobenzene, 2-fluorobenzonitrile, and 2, 4-difluoronitrobenzene.<smiles>[R]c1c([R])c([R])c(Cl)c([R])c1[R]</smiles>

$\mathrm{R}=-\mathrm{H},-\mathrm{NO}_{2},-\mathrm{CF}_{3},-\mathrm{CHF}_{2,}-\mathrm{CHO},-\mathrm{CN}$.

Scheme 2

4-Fluoronitrobenzene (1) Yield: $86.0 \%$, B.P: $204-205^{\circ} \mathrm{C}$, Purity (GC): $99.9 \%$, IR $v_{\max }\left(\mathrm{cm}^{-}\right.$ $\left.{ }^{1}\right): 3122,3090,1915,1620,1592,1520,1493,863,851,747,680,616,491 .{ }^{1} \mathrm{H}$ NMR $\left(500 \mathrm{MHz}, \mathrm{CDCl}_{3}\right): \delta 7.1(2 \mathrm{H}, \mathrm{dd}), 8.2(2 \mathrm{H}, \mathrm{dd}),{ }^{13} \mathrm{C}$ NMR: : $\delta 164.8\left(-\mathrm{C}-\mathrm{NO}_{2}\right), \delta 167.4(-\mathrm{C}-$ $\mathrm{CF}),{ }^{19} \mathrm{~F}$ NMR: $\delta-119(1 \mathrm{~F})$. GCMS: Molecular ion $\mathrm{m} / \mathrm{z}$ (int. \%) 141(100) $[\mathrm{M}]^{+}, 95(88)[\mathrm{M}-$ $\left.\mathrm{NO}_{2}\right]^{+}, 75(22)\left[\mathrm{M}-\mathrm{NO}_{2}-\mathrm{F}\right]^{+}$.

2-Fluoronitrobenzene (2) Yield: $87.4 \%$, B.P: $215^{\circ} \mathrm{C}$, Purity (GC): $99.4 \%$, IR $v_{\max }\left(\mathrm{cm}^{-1}\right)$ : $3110,1599,1526,1483,1345,1313,1239,1141,1032,954,862,810,776,657,540,513 .{ }^{1} \mathrm{H}$ NMR $\left(500 \mathrm{MHz}, \mathrm{CDCl}_{3}\right): \delta 7.4(1 \mathrm{H}, \mathrm{m}), 7.7(1 \mathrm{H}, \mathrm{m}), 8.1(2 \mathrm{H}, \mathrm{m}) .{ }^{13} \mathrm{C}$ NMR: $\delta 154.09$ (-C$\left.\mathrm{NO}_{2}\right), \delta 156.7$ (-C-CF), ${ }^{19} \mathrm{~F}$ NMR: $\delta-117(1 \mathrm{~F}, \mathrm{~s})$. GCMS: Molecular ion m/z (int. \%) 141(100) $[\mathrm{M}]^{+}, 75(96)\left[\mathrm{M}-\mathrm{NO}_{2}-\mathrm{F}\right]^{+}, 95(86)\left[\mathrm{M}-\mathrm{NO}_{2}\right]^{+}$.

2-Fluorobenzonitrile (3) Yield: $92.0 \%$, B.P: $235-237{ }^{\circ} \mathrm{C}$, Purity (GC): $99.4 \% \mathrm{IR} v_{\max }\left(\mathrm{cm}^{-1}\right)$ : $3078,2237,1612,1586,1491,1453,1240,1211,1101,1029,836,757,562,485,455 .{ }^{1} \mathrm{H}$ NMR $\left(500 \mathrm{MHz}, \mathrm{CDCl}_{3}\right): \delta 7.2(1 \mathrm{H}, \mathrm{m}), 7.3(1 \mathrm{H}, \mathrm{m}), 7.6(2 \mathrm{H}, \mathrm{m}) .{ }^{13} \mathrm{C} \mathrm{NMR}: \delta 161.7(-\mathrm{C}-$ $\mathrm{CN}), \delta 164.3(-\mathrm{C}-\mathrm{CF}),{ }^{19} \mathrm{~F}$ NMR: $\delta-102.9(1 \mathrm{~F}, \mathrm{~s})$. GCMS: Molecular ion $\mathrm{m} / \mathrm{z}$ (int. \%) 121(100) $[\mathrm{M}]^{+}, 94(31)[\mathrm{M}-\mathrm{CN}]^{+}, 75(6)[\mathrm{M}-\mathrm{CN}-\mathrm{F}]^{+}$.

2,4-difluoronitrobenzene (4) Yield: $92.0 \%$, B.P: $203-204{ }^{\circ} \mathrm{C}$, Purity (GC): $99.6 \%$ IR $v_{\max }$ $\left(\mathrm{cm}^{-1}\right)$ : 3088, 1604, 1534, 1495, 1418, 1347, 1255, 1122, 1195, 819, 776, 747, 674, 586, 534, 461. ${ }^{1} \mathrm{H}$ NMR (500MHz, CDCl $): \delta 7.1(2 \mathrm{H}, \mathrm{m}), 8.2(1 \mathrm{H}, \mathrm{m}) .{ }^{13} \mathrm{C}$ NMR: $\delta 157.9\left(-\mathrm{C}_{3} \mathrm{NO}_{2}\right), \delta$ 164.2 (-C-CF), $\delta 166.9$ (-C-CF), ${ }^{19} \mathrm{~F}$ NMR: $\delta-111.5(1 \mathrm{~F}, \mathrm{~s}), \delta-97.9(1 \mathrm{~F}, \mathrm{~s})$. GCMS: Molecular ion $\mathrm{m} / \mathrm{z}$ (int. \%) $159(100)[\mathrm{M}]^{+}, 113(99)\left[\mathrm{M}-\mathrm{NO}_{2}\right]^{+}, 75(11)\left[\mathrm{M}-\mathrm{F}-\mathrm{FNO}_{2}\right]^{+}$.

\section{Results and Discussion}

The ionic liquids 1-butyl-3-methylimidazolium tetrafluoroborate (IL-1) and 1-butyl-3methylimidazolium hexafluorophosphate (IL-2) were used for fluorination depending upon the solubility of reactant at specific temperature. Ionic liquid containing imidazolium cation can act as powerful media for fluorination reaction. The ionic liquids facilitates the fluorination reactions and it can be completed at below $200{ }^{\circ} \mathrm{C}$, while the similar reaction in organic solvents are performed at much higher temeperature ${ }^{10}$. Results show that excess of potassium fluoride is not required. The equivalence of potassium fluoride used depends 
upon number of halogen to be replaced and unwanted by-product formation can avoided by careful selection of reaction temperature. Mono-chloro, di-chloro and tri-chlorobenzene do not undergo fluorination reaction as they do not contain any deactivating group in the ring system but 4-chloronitrobenzene, 2-chloronitrobenzene, 2,4 di-chloronitrobenzene undergo fluorination and are transformed to corresponding aryl fluoride in excellent to very good yields in ionic liquid-1. In case of tri-chloronitobenzene only difluorinated nitro compound formed, exchange of third chloride was not observed even after 12-14 hrs. The fluorinated products are high in purity and do not require further purification. Several fluorination reactions were performed as mentioned in Table 1.

In conventional fluorination techniques, nitro group functions as leaving group and it is preferentially displaced even in the presence of chloride substituents, presumably because the Meisenheimer complex derived from attack at the carbon bearing the nitro group is more stabilized. This particular problem was overcame by the use of ionic liquid where rate of fluorodenitration is reduces drastically (Table 1, entry 4). Recycle and reuse of ionic liquids is another benefit of this protocol.

Table 1. Synthesis of aryl fluorides from aryl chlorides using ionic liquids

\begin{tabular}{|c|c|c|c|c|c|c|c|}
\hline $\begin{array}{l}\text { Entry } \\
\text { No }\end{array}$ & Substrate & Product & $\begin{array}{l}\text { Time } \\
\text { (h) }\end{array}$ & Temp $\left({ }^{\circ} \mathrm{C}\right)$ & $\begin{array}{l}\text { Yield } \\
(\%)\end{array}$ & $\begin{array}{l}\text { Purity } \\
(\%)\end{array}$ & $\begin{array}{l}\mathrm{ILs}^{\#} \\
\text { Used }\end{array}$ \\
\hline 1 & & & 9 & 180 & 86 & 99.9 & 1 \\
\hline 2 & & & 12 & $150-160$ & 87.4 & 99.4 & 1 \\
\hline 3 & & & 6 & $195-200$ & 92 & 99.4 & 1 \\
\hline 4 & & & 10 & $160-165$ & 92 & 99.6 & 1 \\
\hline $5^{* *}$ & & & 11 & $150-160$ & -- & -- & 1,2 \\
\hline $6^{* * *}$ & & & 12 & $150-160$ & -- & -- & 1,2 \\
\hline
\end{tabular}

\footnotetext{
${ }^{\#}$ Ionic liquid used for fluorination, ** Expected fluorinated product not formed.
} *** Using recycled ionic liquid-I 


\section{Conclusion}

We have developed a new and highly efficient, neat reaction protocol for the synthesis of fluorinated organic compounds using halex reaction in ionic liquids. The properties and behavior of the ionic liquid can be adjusted to suit reaction type. We have shown that a correct ionic liquid can be a solvent of choice for halex reactions. It not only effectively replaces conventional organic solvent but also increases the nucleophilicity of fluoride ion as evident by relatively lower reaction temperature and improved yield. Often the ionic liquid can be recycled, and this leads to reduction of process cost. Further the reactions in ionic liquids are not difficult to perform and usually require no special apparatus or methodologies. The reactions are often quicker, require comparative lower temperature and easier to carry out than in conventional organic solvents. Low effluents and recyclability of ionic liquids for several runs makes the process more viable for commercialization.

\section{Acknowledgements}

Author thanks Jaipur National University, Jaipur, Rajasthan, India for providing necessary facilities and support.

\section{References}

1. Earle M J, McCormac P B and Seddon K R, Chem Comm., 1988, 2245; DOI: $10.1039 / \mathrm{A} 806328 \mathrm{~A}$

2. Armstrong D W, He L and Liu Y S, Anal Chem., 1999, 71, 3873-3876; DOI: $10.1021 /$ ac990443p

3. McEwen A B, Ngo H L, LeCompte K and Goldman J L, J Electrochem Soc., 1999, 146, 1687-1695; DOI: 10.1149/1.1391827

4. Fustero S, Soloshonok V A and Liu H, Chem Rev., 2014, 114, 2432; DOI: $10.1021 / \mathrm{cr} 4002879$

5. Dimagno S G and Sun H, Current Topics in Medicinal Chemistry, 2006, 6, 1473 1482; DOI: $10.2174 / 156802606777951127$

6. Clark J H, Wails D and Bastock T W, Aromatic Fluorination, CRC Press, Boca Raton, 1996.

7. Adams D J and Clark J H, Chemical Society Reviews, 1999, 28(4), 225-231; DOI: 10.1039/A808707E

8. Pleschke A, Marhold A, Schneider M and Roschenthaler G V, J Fluorine Chem., 2004, 125, 1031-1038; DOI:10.1016/j.jfluchem.2004.01.030

9. Langlois B, Gilbert L and Forat G, Industrial Chemistry Library, 1996, 8, 244-292; DOI:10.1016/S0926-9614(96)80019-0

10. Zhong P, Hu H and Guo S, Synth Comm., 2004, 34, 4301-4311; DOI: 10.1081/SCC-200039365

11. Sasson Y, Negussie S, Royz M and Mushkin N, Chem Comm., 1996, 3, 297-298; DOI: $10.1039 /$ CC9960000297

12. Wilkes J K and Zaworotko M J, J Chem Soc Chem Comm., 1992, 19, 965-967; DOI: $10.1039 / \mathrm{C} 39920000965$

13. Xavier C and Elizabeth D W, Org Syn., 2005, 82, 166; DOI: 10.15227/orgsyn.082.0166

14. Dupont J, Crestina S C, Paulo A Z and Roberto F D, Org Syn Coll., 2004, 10, 184; DOI:10.15227/orgsyn.079.0236 